\title{
MODO DE PRODUÇÃo E A PEDAGOGIA HISTÓRICO-CRÍTICA
}

\author{
Dermeval Saviani ${ }^{1}$
}

Por: Maria de Fátima Rodrigues Pereira e Elza Margarida de Mendonça Peixoto

Os editores da Revista Germinal não tiveram dúvidas ao escolher Dermeval Saviani como o primeiro entrevistado. As contribuições do autor, um clássico da História da Educação e da Pedagogia Marxista no Brasil, são essenciais para pensar a superação da pedagogia do capital e a produção da pedagogia comunista. Entre junho e agosto de 2008, deram-se os estudos sobre a obra do autor, a estruturação do roteiro que serviria de base às reflexões do mestre, e a produção das respostas. O roteiro enviado ao Prof. Saviani privilegiou questões que permitiram ao autor precisar (1) o caráter ontológico da categoria modo de produção na obra de Marx e Engels; (2) as contribuições deste constructo teórico ao modo como o historiador da educação e pedagogo vai conduzir suas pesquisas sobre a História da Educação na formação social brasileira e sobre a produção da pedagogia histórico-crítica; (3) a proposição da história, em uma perspectiva dialética, como eixo articulador de um currículo que atenda às exigências postas pela sociedade moderna à escola; (4) os nexos entre modo de produção, trabalho e educação, precisando sua posição ante o debate "educação tecnológica" e "educação politécnica"; (5) retomar a avaliação que vem fazendo sobre a história da política educacional brasileira e sua posição sobre a política que levaria à uma educação de qualidade; (6) as tarefas que considera centrais aos pedagogos marxistas; e (7) indicar um programa de historicização que deve ser seguido pelos professores, cabendo à educação formal institucionalizada levar a "elaboração superior da estrutura em superestrutura na consciência dos homens". O resultado é um texto de síntese sobre a trajetória teórica do pesquisador, indispensável para recuperar os nexos da pedagogia histórico-crítica com o marxismo.

G. O senhor tem incansavelmente, haja vista o conjunto da sua obra enquanto pesquisador e professor, se debruçado sobre diferentes temas relacionados à educação no Brasil, analisando-os filosófica e historicamente a partir dessa visão crítica do homem e da vida. Quais seriam, no seu entender, os princípios, os elementos intrínsecos a uma educação escolar que tivesse como pressuposto a prática social que se expressa pelo constructo modo de produção?

S.: Primeiramente importa observar que o conceito de modo de produção, tal como formulado e desenvolvido por Marx, não está circunscrito, como se tende a interpretar, à economia. É, antes, um conceito ontológico, pois diz respeito ao modo como é produzido o próprio ser dos homens. É isto o que se manifesta em sua primeira formulação na Ideologia alemã e em seu desenvolvimento ulterior nas notas preparatórias (Grundrisse) para $O$ capital, como se pode ver no "Prefácio à Contribuição à 
Crítica da economia política" e nas "Formações econômicas pré-capitalistas". Nesses dois últimos casos o conceito já recebe uma determinação concreta, especificando-se os modos fundamentais que se manifestaram historicamente, nomeados como comunismo primitivo, asiático, escravismo antigo, feudal e burguês moderno. Assim, o princípio fundamental inerente ao conceito de modo de produção é que aquilo que os homens são decorre diretamente do modo como eles produzem sua existência. Em consequência, o modo de produção determina todas as manifestações da existência humana, desde as formas da produção dos bens materiais destinados ao consumo e à troca, até as formas da consciência. Portanto, a forma de manifestação da educação também irá variar de maneira correspondente à variação do conceito de modo de produção. Assim, a educação vigente no comunismo primitivo terá características diversas em relação àquela produzida no âmbito do modo de produção asiático, antigo, feudal ou no modo burguês moderno, isto é, capitalista.

G. Que relações são possíveis de estabelecer entre a Pedagogia Histórico-Crítica formulada pelo senhor e que vem recebendo contribuições de outros estudiosos e a visão ontológica $e$ gnosiológica do constructo Modo de produção?

S.: A Pedagogia histórico-crítica foi construída, sem dúvida, tendo por base o conceito de modo de produção, em sua acepção marxiana. Com efeito, ao definir a educação como "o ato de produzir, ativa e intencionalmente, em cada indivíduo singular, a humanidade que é produzida histórica e coletivamente pelo conjunto dos homens", essa teoria pedagógica está se reportando explicitamente ao conceito de "modo de produção", pois entende que do modo como os homens produzem sua existência deriva o modo como se produz a educação. Evidentemente, na primeira formulação da pedagogia histórico-crítica parti da compreensão do modo como a existência humana vem sendo produzida sob a forma capitalista, procurando identificar os problemas que, uma vez postos por esse modo de produção, exigem a intervenção da prática educativa. Mas já na Apresentação da primeira edição do livro, em 1991, anunciei uma pesquisa de longo alcance tendo como objetivo "rastrear o percurso da educação desde suas origens remotas, tendo como guia o conceito de modo de produção". E, em seguida, indiquei o objeto da investigação nos seguintes termos: "trata-se de explicitar como as mudanças das formas de produção da existência humana foram gerando historicamente novas formas de educação, as quais, por sua vez, exerceram influxo sobre o processo de transformação do modo de produção correspondente".

G. Em 2004, na Conferência de abertura da IV Jornada do Grupo de Estudos e Pesquisas Histedbr, realizada em Maringá, entre 5 e 7 de julho, e hoje publicada no livro Educação em Debate (Editora Autores Associados) o senhor discorreu sobre o tema "Estágio Atual e Uma Nova Perspectiva para a História da Educação". Já ao final de sua fala, o senhor aponta que a história seria a matéria "que ocuparia o lugar central no novo princípio educativo da escola no nosso tempo". Pode explicar melhor o seu pensamento a respeito? Seria a história a disciplina a se constituir num eixo articulador do conhecimento escolar? E que perspectiva de história daria conta desse princípio educativo? 
S.: Nesse texto que, aliás, eu retomo no livro A pedagogia no Brasil: história e teoria, que está sendo lançado neste mês de agosto, discuto, inspirado na reflexão de Gramsci sobre a eficácia da escola tradicional, centrada no latim e no grego, o problema do eixo articulador do currículo de uma nova escola que, atendendo às exigências postas pela sociedade moderna, venha a reproduzir, nas novas condições, o mesmo grau de eficácia de que era dotada a escola clássica. E ocorreu-me, então, que esse eixo articulador deverá ser encontrado na História. Isso porque, como flui de toda a teoria desenvolvida por Marx, o homem é essencialmente um ser histórico. Ou seja: é pela história que nós nos formamos como homens e é por ela que nós nos conhecemos e ascendemos à plena consciência do que somos. Pelo estudo do que fomos no passado descobrimos ao mesmo tempo o que somos no presente e o que podemos vir a ser no futuro. Aliás, o próprio Gramsci, ao demonstrar a eficácia da escola clássica, destacou que a força educativa do latim e do grego repousava no fato de que o estudo dessas línguas não era feito em abstrato, mas em concreto, pois ao estudá-las se reconstruía a história dos povos que as falavam. E era exatamente o mergulho na história desses povos que se revestia de um grande poder educativo que conferia às elites do velho regime uma sólida formação. Com a derrocada da velha sociedade também essa escola foi posta em cheque. E surgiu a necessidade de uma nova escola adequada aos novos tempos. E Gramsci nos assegura que essa nova escola deverá surgir inevitavelmente. Mas acrescenta que não será fácil encontrar o eixo articulador da nova escola que venha a substituir a contento o papel antes desempenhado pelo latim e pelo grego. É nesse contexto que emergiu em meu espírito a ideia de que o novo eixo articulador nos é fornecido pela História, ideia traduzida na seguinte indagação: Que outra maneira nós teríamos de produzir, em cada indivíduo singular, a humanidade que é produzida histórica e coletivamente pelo conjunto dos homens senão fazendo com que as novas gerações mergulhem na própria história e, aplicando o critério do "clássico", permitir-lhes vivenciar os momentos mais significativos dessa prodigiosa aventura humana no tempo? Eis como, me parece, será possível reorganizar integralmente a escola em torno de um novo eixo articulador. Mas cabe advertir que não se trata simplesmente de colocar um peso maior na disciplina "História". Como eixo a história será o elemento em torno do qual todo o currículo será estruturado, isto é, todas as disciplinas estarão impregnadas de historicidade, serão atravessadas pelo conteúdo histórico. Como o que está em causa nessa proposta é o próprio conteúdo objetivo da história, poderíamos dizer que ela se impõe para além das diversas perspectivas de compreensão da história. No entanto, é igualmente claro que essa maneira de encarar a história, a possibilidade de tomá-la como eixo articulador dos currículos formativos e o próprio entendimento da história como processo objetivo indicam tratar-se da concepção dialética da história cuja matriz foi explicitada no âmbito do marxismo.

\section{G. Quais são hoje as abordagens que estão postas entre os pesquisadores brasileiros com relação ao trabalho como princípio educativo e a formação politécnica? Qual a sua posição?}


S.: Preliminarmente penso ser pertinente observar que o entendimento do trabalho como princípio educativo se encontra em perfeita consonância com o conceito de modo de produção, pois é pelo trabalho que o homem produz sua existência, o que nos permite afirmar que o modo como o homem trabalha determina todas as demais formas da existência humana. E a ideia de politecnia ou formação politécnica coloca exatamente a exigência de explicitação da relação entre educação e trabalho como via de superação da oposição entre educação e trabalho imperante nas sociedades de classe. Nessa condição a proposta da politecnia se inscreveu na tradição socialista em contraposição à concepção burguesa de educação. No entanto, motivada pelos estudos filológicos de Manacorda sobre as obras de Marx, emergiu recentemente entre os pesquisadores a ideia de que a expressão "educação politécnica" corresponderia à concepção burguesa, sendo que Marx teria dado preferência à expressão "educação tecnológica". Minha posição a respeito é que em Marx aparecem indistintamente as duas expressões com significados equivalentes. E, embora tenha surgido no seio da burguesia a denominação relativa às escolas politécnicas, esse termo só subsiste em casos restritos de escolas de engenharia. Em contrapartida, a burguesia se apropriou definitivamente da expressão "educação tecnológica" ao passo que "educação politécnica" passou a identificar a concepção socialista tanto internamente, isto é, para os próprios socialistas, como externamente, isto é, também a burguesia a considera identificada com o socialismo e, por isso, tende a rejeitar a noção de politecnia. Por outro lado, fora do campo dos especialistas, isto é, os pesquisadores da área, é comum que os professores confundam politecnia com polivalência. Por isso é necessário observar que a substituição do modelo taylorista-fordista, caracterizado por formas rígidas de produção, pelo modelo toyotista, marcado por formas flexíveis, trouxe à baila a proposta de educação polivalente e não a educação politécnica, como por vezes se acredita.

G. No texto - O Plano de Desenvolvimento da Educação: Análise do Projeto do MEC, no qual o senhor analisa o PDE, publicado no n. 100 da Revista Educação e Sociedade o senhor retoma a questão dos recursos financeiros e humanos para a efetivação de uma "educação de qualidade". $O$ que seria uma educação de qualidade e que recursos são necessários para garanti-la? $O$ que significa afirmar que o governo não criou um sistema de educação, mas um sistema de avaliação?

S.: Claro que uma educação de qualidade não pode se realizar sem significativos investimentos em infraestrutura e, especialmente, nos recursos humanos com destaque para os professores. Não obstante, em flagrante contradição com o discurso dominante que afirma considerar a educação como a área prioritária que, na chamada "sociedade do conhecimento", é o elemento estratégico sem o qual qualquer empreendimento tende a fracassar, tanto os políticos como os empresários resistem a investir em educação pautando-se recorrentemente pelo princípio do máximo de resultados com o mínimo de dispêndio, buscando sempre reduzir os custos educacionais. Assim, embora na discussão da nova LDB o governo tenha recusado a proposta de instituição de um sistema nacional de educação, o mesmo governo patrocinou e criou, por meio da referida LDB, um sistema nacional de 
avaliação que colocou sob a responsabilidade da União a avaliação de toda a educação no país, desde as creches até a pós-graduação. Com isso a União enfeixou em suas mãos o controle de toda a educação, ao mesmo tempo em que descentralizou os custos transferindo-os para estados, municípios e as diferentes instâncias da sociedade civil. Contra essa tendência tenho defendido: a) a necessidade da construção de um sistema nacional de educação coordenado pela União em regime de colaboração com estados e municípios; b) para financiar o sistema nacional de educação caberia, em consonância com o discurso dominante que atribui à educação o papel chave na chamada "sociedade do conhecimento", considerar a educação como o eixo de um projeto de desenvolvimento nacional carreando para ela todos os recursos disponíveis porque, definida como área estratégica é a partir dela que seria mobilizado o desenvolvimento da sociedade em seu conjunto abrangendo os diferentes setores econômicos, sociais, políticos e culturais. Nessas condições a implantação do sistema nacional de educação promoveria a universalização da educação básica garantindo sua oferta, com o mesmo padrão de qualidade, a todos os brasileiros que teriam assegurado não apenas o acesso, mas também a conclusão da educação básica, cujos níveis e modalidades seriam desenvolvidos de forma articulada entre si e com a educação superior à qual caberia a responsabilidade de formar os professores para a educação básica.

G. Que temas e práticas educativas são centrais aos educadores que se colocam no campo do marxismo? Que papel assumem os conteúdos e as ideologias em uma pedagogia revolucionária?

S.: Eu diria que a tarefa central dos educadores que se colocam no campo do marxismo implica em um duplo e concomitante movimento: trata-se de empreender a crítica à educação burguesa evidenciando seus mecanismos e desmistificando sua justificação ideológica; ao mesmo tempo, cabe realizar o segundo movimento que implica reorganizar a prática educativa de modo a viabilizar, por parte das camadas dominadas à frente o proletariado, o acesso ao saber elaborado. Esse acesso significa a apropriação dos conteúdos sistematizados dos quais os trabalhadores necessitam para potencializar sua luta em defesa de seus interesses contra a dominação burguesa. É por esse caminho que a ideologia proletária, isto é, a expressão elaborada dos interesses dos trabalhadores poderá se configurar com um poder lógico e uma força política capaz de disputar com a ideologia burguesa a hegemonia da sociedade. Nesse processo a escola desempenha papel fundamental, pois é ela que abre, por meio da alfabetização, as portas da cultura letrada no âmbito da qual se dá a elaboração do saber e o desenvolvimento do conhecimento científico. Portanto, os educadores que se colocam no campo do marxismo deverão ter clareza de que, se a burguesia se serve do saber elaborado para reforçar sua dominação, isso se deve ao fato de que ela busca se apropriar com exclusividade dessa forma de saber, excluindo dela os trabalhadores. Segue-se, pois, que o saber elaborado é colocado a serviço da burguesia, o que lhe dá a aparência de que se trata do próprio saber burguês. Na medida, porém, em que, pela análise do desenvolvimento histórico propiciado pela teoria marxista, nos damos conta de 
que o saber elaborado não é inerentemente burguês, mas é produzido pelo conjunto dos homens ao longo da história, nos defrontamos com a seguinte tarefa: desarticular da ideologia burguesa o saber elaborado e rearticulá-lo em torno dos interesses dos trabalhadores. É esse o trabalho que nos cabe desenvolver como educadores, como o têm evidenciado os principais teóricos do marxismo. Assim, Gramsci nos recorda que "é através da crítica da civilização capitalista que se forma ou está se formando a consciência unitária do proletariado, e crítica quer dizer cultura, e não já evolução espontânea e naturalística"2. E acrescenta: "Se é verdade que a história universal é uma cadeia dos esforços que o homem fez para libertar-se tanto dos privilégios como dos preconceitos e da idolatria, não se compreende por que o proletariado, que um outro elo quer juntar a essa cadeia, não deva saber como e por que e de quem tenha sido precedido, e qual a vantagem que pode tirar desse saber."3 Igualmente Lênin frisa a importância da apropriação da cultura acumulada por parte do proletariado afirmando taxativamente que, embora justas, as críticas à velha escola não nos deveria levar à conclusão de que não se faz necessário assimilar os conhecimentos acumulados pela humanidade: "seria equivocado pensar que basta aprender as consignas comunistas, as conclusões da ciência comunista, sem assimilar a soma de conhecimentos dos quais é consequência o próprio comunismo.”4 E, especificamente, no que se refere ao tema da cultura proletária Lênin entende que tal cultura "só pode ser criada conhecendo com precisão a cultura que criou a humanidade em todo o seu desenvolvimento e transformando-a". ${ }^{5}$ Com efeito, prossegue, "a cultura proletária não surge do nada, não é uma invenção dos que se chamam especialistas em cultura proletária. Isso é pura tolice”. E arremata: "A cultura proletária tem que ser o desenvolvimento lógico do acervo de conhecimentos conquistados pela humanidade sob o jugo da sociedade capitalista, da sociedade latifundiária, da sociedade burocrática". ${ }^{6}$

\section{G. Que outros temas entende como relevantes para a discussão Modo de Produção e educação?}

S.: Claro que nós poderíamos discorrer longamente sobre uma série de temas importantes no âmbito da relação entre modo de produção e educação, como o lugar da educação no interior da contradição entre as relações sociais de produção e forças produtivas, o tema do trabalho, da formação politécnica, da era das máquinas inteligentes, do reino da necessidade versus reino da liberdade, entre muitos outros. Mas penso que o tema fundamental é o da historicização. Acho que o empenho a que se devem dedicar permanentemente os educadores críticos e progressistas, em especial aqueles que se situam no campo do marxismo, é o de historicizar todos os conteúdos, todas as ideias e propostas, todos os conhecimentos, situando-os no curso do desenvolvimento da humanidade no qual se revela plenamente o seu significado. Com efeito, como já se assinalou, o elemento educativo por excelência é a própria história, pois é nela que objetivamente os homens se constituem como homens. À educação formal, institucionalizada, cabe elevar esse fenômeno objetivo à plenitude da consciência subjetiva 
operando a catarse, isto é, a "elaboração superior da estrutura em superestrutura na consciência dos homens", conforme a definição de Gramsci.

\section{Notas}

${ }^{1}$ Doutorado em Filosofia da Educação pela Pontifícia Universidade Católica de São Paulo, Brasil(1971). Pós-Doutorado pelo Universita di Bologna, Itália(1995). Livre Docência pela Universidade Estadual de Campinas, Brasil (1986). Email: dermevalsaviani@yahoo.com.br

2 GRAMSCI, A. Scriti giovanili (1914-1918). Torino: Einaudi, 1975. p. 25.

${ }^{3}$ Ibidem, p. 26.

${ }^{4}$ LENIN, Vladimir Ilitch. Tareas de las organizaciones juveniles. In: t. 11, p.203-220. p. 206.

${ }^{5}$ Ibidem, p. 207.

${ }^{6}$ Ibidem. 